\title{
Magnesium-Stabilised Transition Metal Formyl Complexes: Structures, Bonding, and Ethenediolate Formation
}

\author{
Joseph M. Parr, ${ }^{\text {a }}$ Andrew J. P. White, ${ }^{\text {a }}$ and Mark R. Crimmin*a \\ Corresponding author. Email: m.crimmin@imperial.ac.uk

\begin{abstract}
${ }^{a}$ Molecular Sciences Research Hub, Department of Chemistry, Imperial College London, 82 Wood Lane, White City, Shepherds Bush, London, W12 OBZ, UK.
\end{abstract}

\begin{abstract}
Herein we report the first comprehensive series of crystallographically characterised transition metal formyl complexes. In these complexes, the formyl ligand is trapped as part of a chelating structure between a transition metal ( $\mathrm{Cr}, \mathrm{Mn}, \mathrm{Fe}, \mathrm{Co}, \mathrm{Rh}, \mathrm{W}$, and $\mathrm{Ir})$ and a magnesium ( $\mathrm{Mg})$ cation. Calculations suggest that this bonding mode results in significant oxycarbene-character of the formyl ligand. Electronrich late-transition metal complexes have the highest oxycarbene-character to the bonding and are the most stable in solution. Further reaction of a heterometallic $\mathrm{Cr}$---Mg formyl complex results in a rare example of $\mathrm{C}-\mathrm{C}$ coupling and formation of an ethenediolate complex. These results show that well-defined transition metal formyl complexes are potential intermediates in the homologation of carbon monoxide.
\end{abstract}

\section{Introduction}

Transition metal formyl complexes are important intermediates in the reduction of carbon monoxide (CO) and carbon dioxide $\left(\mathrm{CO}_{2}\right) .{ }^{1}$ For example, transition metal formyl species have been proposed as key intermediates in the reduction of $\mathrm{CO}$ with $\mathrm{H}_{2}$ to form linear alkanes in the Fischer-Tropsch (F-T) process. ${ }^{2-}$ ${ }^{7} \mathrm{~F}-\mathrm{T}$ catalysis is an industrially important process that in the long-term could provide a sustainable approach for the valorisation of $\mathrm{CO} / \mathrm{H}_{2}$ from biomass or remediation of $\mathrm{CO}_{2}$ by exploiting the water-gas shift reaction..$^{8-13}$

Despite their importance, the detailed study of transition metal formyl complexes has been hampered by their low stability. Early studies established that these species undergo facile $\alpha$-elimination reaction to form the corresponding hydrido carbonyl complexes. ${ }^{13-25}$ The reaction is potentially reversible, but in most cases the hydrido carbonyl is thermodynamically favoured (Scheme 1). ${ }^{26-29}$ 


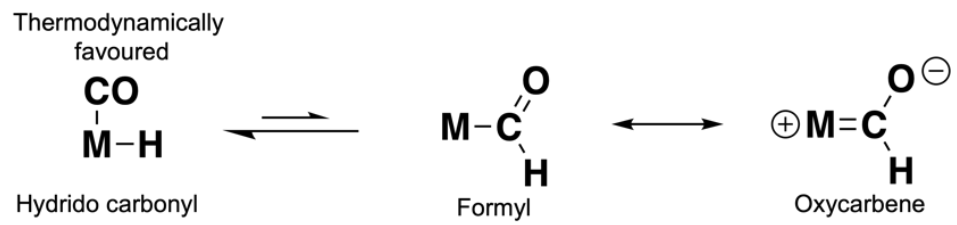

Scheme 1. Transition metal-hydride to metal formyl equilibrium and canonical forms of a transition metal formyl complex.

A survey of the Cambridge Crystallographic Data Centre (CCDC) database reveals that despite nearly 50 years of research into transition metal formyl complexes, only a modest number of transition metal formyl complexes have been structurally characterised (supporting information, Figure S11 and Table S2). The paucity of data has meant that there is currently no systematic study into the effect of the transition metal on the bonding of structurally characterised formyl complexes. Furthermore, the role of well-defined transition metal formyl complexes as intermediates in F-T type chemistry is not well established. ${ }^{30-32}$

One potential approach to increase the thermodynamic stability of transition metal formyl complexes is to increase the oxycarbene character of the ligand (Scheme 1). Increased oxycarbene character is expected to increase the metal ligand binding energy and therefore impact the position of the equilibrium between the metal formyl and metal hydrido carbonyl. ${ }^{33-36}$

In this study, we document the preparation, structural characterisation, and bonding analysis (NBO, ETSNOCV, QTAIM) of the first complete series of transition metal formyl complexes ( $\mathrm{M}=\mathrm{Cr}, \mathrm{Mn}, \mathrm{Fe}, \mathrm{Co}, \mathrm{Rh}$, $\mathrm{W}$, and Ir). This includes unprecedented examples of crystallographically characterised Cr, Co and Ir formyl complexes. The isolation of these complexes is facilitated by a heterometallic stabilising effect. Through reduction of a series of transition metal carbonyl complexes with a molecular magnesium hydride compound, the formyl ligand can be trapped as part of a chelating structure. Remarkably, further reaction of a chromium formyl complex results in $\mathrm{C}-\mathrm{C}$ bond formation and an ethenediolate species bridging the chromium and magnesium centres. This is an exceedingly rare example in which a well-defined transition metal formyl complex has been shown to be involved in a carbon-carbon bond forming reaction of direct relevance to the F-T process. ${ }^{30}$ 


\section{Results and Discussion}

Reaction of magnesium hydride dimer (1) with a series of transition metal carbonyl complexes (2) in toluene solution furnished the corresponding heterometallic formyl complexes (3) in $21-68 \%$ isolated yields (Scheme 2). These reactions occurred readily at $22{ }^{\circ} \mathrm{C}$ as evidenced through a marked colour changes and diagnostic spectroscopic data. In $\mathrm{C}_{6} \mathrm{D}_{6}$ solution, the transition metal formyl species $3 a-h$ were characterized by singlet resonances between $\delta_{H}=13.05-15.11 \mathrm{ppm}$ and $\delta_{\mathrm{C}}=240-310 \mathrm{ppm}$ in the ${ }^{1} \mathrm{H}$ and ${ }^{13} \mathrm{C}\left\{{ }^{1} \mathrm{H}\right\}$ NMR spectra respectively. Bonding between $\mathrm{H}$ and $\mathrm{C}$ atoms of the $\mathrm{M}-\mathrm{CHO}$ fragment was confirmed by heteronuclear single quantum coherence (HSQC) NMR experiments. Further coupling was apparent in cases of spin active transition metals; the formyl ligand of $3 \mathbf{b}$ shows ${ }^{2} J_{\mathrm{W}-\mathrm{H}}=9.0 \mathrm{~Hz}$, while $\mathbf{3 g}$ shows ${ }^{2} J_{\mathrm{Rh}-\mathrm{H}}=$ $2.1 \mathrm{~Hz}$ and ${ }^{1} J_{\mathrm{Rh}-\mathrm{C}}=56.0 \mathrm{~Hz}$. Bridging magnesium hydride resonances ranged $\delta_{\mathrm{H}}=2.86-3.17 \mathrm{ppm}$ in the ${ }^{1} \mathrm{H}$ NMR spectra. In all cases, 3a-h demonstrate two distinct sets of magnetically inequivalent proton environments for each of the $\beta$-diketiminate ligands.

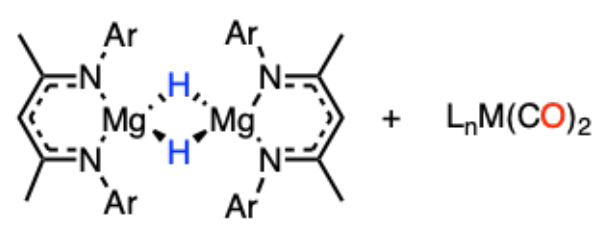

1

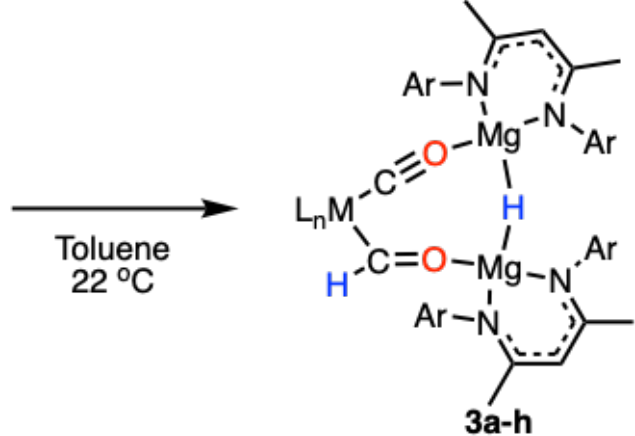

a, $\mathrm{M}=\mathrm{Cr}, \mathrm{L}_{\mathrm{n}}=(\mathrm{CO})_{4}$

b, $M=W, L_{n}=(C O)_{4}$

c, $\mathrm{M}=\mathrm{Fe}, \mathrm{L}_{\mathrm{n}}=(\mathrm{CO})_{3}$

d, $M=C r, L_{n}=\left(\mathrm{C}_{6} \mathrm{H}_{6}\right)(\mathrm{CO})$

e, $M=M n, L_{n}=\left(C p^{\prime}\right)(C O)$

f, $M=C o, L_{n}=\left(C p^{\star}\right)$

$g, M=R h, L_{n}=\left(C p^{*}\right)$

$h, M=I r, L_{n}=\left(C p^{\star}\right)$

Scheme 2. Synthetic procedure for the formation of compounds 3a-h $\left(\mathrm{Ar}=2,6\right.$-diisopropylphenyl, $\mathrm{Cp} \mathrm{p}^{\prime}=$ methylcyclopentadienyl, $\mathrm{Cp}^{*}=$ pentamethylcyclopentadienyl).

The infrared data for complexes 3a-h show characteristic stretching frequencies for both the isocarbonyl and carbonyl ligands (Table S3, Figures S13-21). Terminal carbonyl ligands on 3a-e displayed stretching frequencies at $1916-2067 \mathrm{~cm}^{-1}$, in line with the well-known transition metal carbonyl ligands; gratifyingly, 3f-h showed no stretches in this region. The isocarbonyl, bridging the magnesium to transition metal centre, appear as strong intensity bands at $1674-1791 \mathrm{~cm}^{-1}$. Typical formyl stretches appear at a medium intensity in the range $1530-1630 \mathrm{~cm}^{-1}$, red-shifted from the carbonyl ligands. ${ }^{37,38}$ Complexes $3 a-h$ show stretching frequencies at $1513-1520 \mathrm{~cm}^{-1}$, with the $v(\mathrm{CO})$ stretch for the $\mathrm{M}-\mathrm{CHO}$ fragment potentially masked by the $\mathrm{C}=\mathrm{N}$ stretch of the $\beta$-diketiminate ligand. Formyl ligand $\mathrm{C}-\mathrm{H}$ bonds are observed as weak intensity stretching frequency at $2546-2635 \mathrm{~cm}^{-1}$ for $\mathbf{3 a - b}, \mathbf{3 d}$, and $\mathbf{3 f - h}$; formyl C-H stretches in $\mathbf{3 c}$ and 3e were not observed. 
All eight members of the series (3a-h) have been characterised in the solid state by single crystal X-ray diffraction analysis (Figure 1, Table 1). In all cases these structures showed a key motif involving an 8membered ring comprised of the transition metal and two magnesium sites, along with the formyl, isocarbonyl and hydride ligands. While all complexes demonstrate the same structural type, only in $\mathbf{3 c}$ and $\mathbf{3 f}$ is the structure free from disorder at the transition metal ligands, in the other cases positional disorder between the isocarbonyl and formyl sites of this ring is observed.

Complex 3c, a representative example, crystallises in the P-1 space group, with the five carbon ligands arranged in a trigonal bipyramidal geometry around the iron centre. The formyl ligand occupies the axial position with a $\mathrm{Mg}-\mathrm{H}-\mathrm{Mg}$ bridge to a cis equatorial carbonyl ligand. The iron-carbon formyl bond of 1.935(9) $\AA$ is markedly longer than the isocarbonyl metal-carbon (1.734(8) $\AA$ ) and the averaged metalcarbon carbonyl bonds $(1.81(1) \AA ̊)$.

Within the series 3a-h, M-C bond lengths to the formyl ligand range 1.80(3) - 2.19(2) $\mathrm{A}$. The longest $M-C$ bond lengths are recorded for the most electron deficient $d^{6}$ transition metal fragments (3a-b), while the shortest $\mathrm{M}-\mathrm{C}$ distances are recorded for the most electron rich $\mathrm{d}^{8}$ transition metal fragments (3f-h). At the same time, $\mathrm{C}-\mathrm{O}$ bond lengths of the carbonyl ligands are longest in $\mathbf{3 g - h}$ (Table 1 ). The data suggest that the oxycarbene resonance form of the formyl fragment may become more dominant for more electron rich transition metal fragments. In most cases, the hydride ligand could be located within the Fourier difference map, while the location of this atom should be treated with caution, the $\mathrm{Mg}-\mathrm{H}-\mathrm{Mg}$ bond angles varied $146(1)-160(3)^{\circ}$. This angle is obtuse, presumably to achieve the geometry for the bimetallic magnesium fragment to bridge two mutually cis sites of the transition metal fragment. 

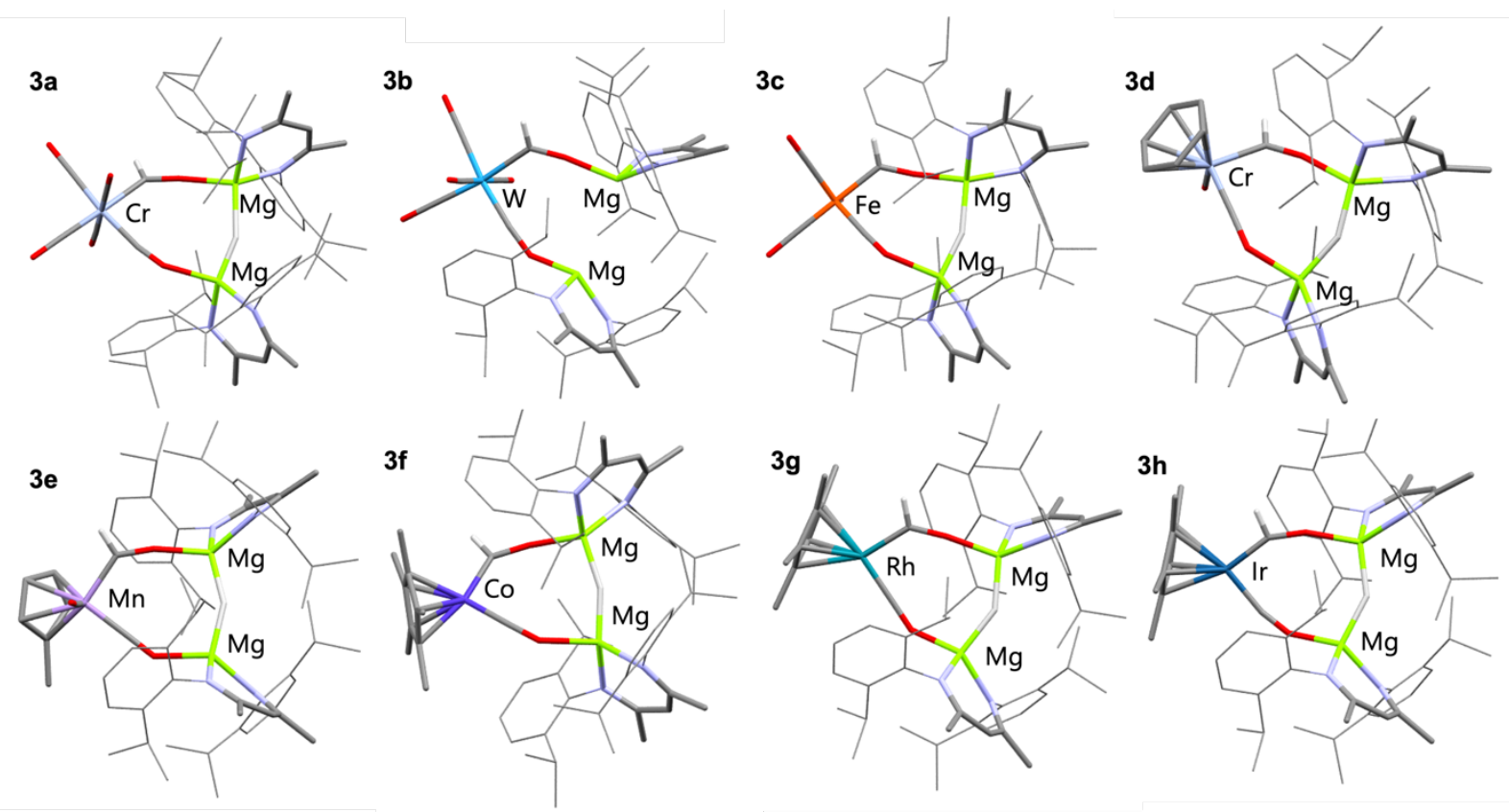

Figure 1. X-ray crystal structures of 3a-h. Solvent molecules and most hydrogen atoms removed for clarity.

\begin{tabular}{cccc}
\hline & $\mathrm{M}-\mathrm{C}(\AA)^{\mathrm{a}}$ & $\mathrm{C}-\mathrm{O}(\AA)^{\mathrm{a}}$ & $\mathrm{M}-\mathrm{C}-\mathrm{O}\left({ }^{\circ}\right)$ \\
\hline 3a & $2.054(9)$ & $1.210(7)$ & $132.0(6)$ \\
3b & $2.19(2)$ & $1.26(2)$ & $130(1)$ \\
3c & $1.935(9)$ & $1.221(2)$ & $128.5(6)$ \\
3d & $1.95(1)$ & $1.234(9)$ & $137.1(8)$ \\
3e & $1.91(2)$ & $1.24(1)$ & $133(1)$ \\
3f & $1.804(8)$ & $1.255(9)$ & $135.9(6)$ \\
3g & $1.920(6)$ & $1.270(5)$ & $134.0(5)$ \\
3h & $1.80(3)$ & $1.27(3)$ & $151(3)$
\end{tabular}

Table 1. Selected structural parameters for $\mathrm{M}-\mathrm{CHO}$ components for complexes 3. ${ }^{\text {a }}$ average bond length, provided with pooled estimated standard deviation (ESDs) in parentheses where possible. 
The electronic structure and bonding interaction between the formyl ligand and transition metal centre were investigated using Density Functional Theory (DFT). Calculations were performed in Gaussian 09 and Orca 4.2.1. Natural Bonding Orbital (NBO) and Extended Transition State-Natural Orbital Chemical Valence (ETS-NOCV) methods were employed to interrogate the bonding interactions in 3a-h. Structures were optimised using the $\omega B$ 97X-D functional, a hybrid basis set was used 6-31G** $(C, H), 6-311+G^{*}(N, O)$ while the SDDAll pseudopotential and associated basis sets were used to describe $\mathrm{Mg}$ and $\mathrm{M}$ centres. ${ }^{39-44}$

NBO calculations were performed on complexes 3a-h. Analysis of the Natural Population Analysis (NPA) charges suggests that the binding interaction between the transition metal fragment and dimagnesium hydride fragment is largely ionic. The hydride $(-0.8)$ and oxygen atoms $(-0.9)$ directly attached to magnesium bear significant negative charge while these magnesium sites themselves are highly electropositive (+1.8). Comparison of data for $\mathbf{3 a}$ and $\mathbf{3 b}$ to the theoretical models $\left[\mathrm{M}(\mathrm{CO})_{5}(\mathrm{CHO})\right]^{-}(\mathrm{M}=$ $\mathrm{Cr}$, Mo, W) shows little change in the NPA charges, supporting the idea that there is a large ionic contribution to the bonding between the transition metal and main group fragments. QTAIM calculations point to the same conclusion, with hydride $(-0.8)$, oxygen $(-1.4)$ and magnesium $(+1.8)$ charges complimenting the NBO data (Table S5-6, S9).

Comparison of both the NPA charges and Wiberg bond indices (WBI) for selected sets of complexes within the series allows the influence of $\mathrm{d}^{\mathrm{n}}$ electron count, ligand, and transition metal on the bonding to be deconvoluted. The trends in these data suggest that, in general, increasing $d^{n}$ electron count (3a vs $3 c$ ), increasing the electron-donating ability of the ligand ( $\mathbf{3 a}$ vs $\mathbf{3 d}$ ), and descending the triad ( $\mathbf{3} \mathbf{f}$ vs $\mathbf{3 g}$ vs $\mathbf{3 h}$ or $\mathbf{3 a}$ vs $\mathbf{3 b}$ ), all increase the oxycarbene character of the formyl ligand. This is evident from increases in the $\mathrm{M}-\mathrm{C} \mathrm{WBI}$, decreases in the $\mathrm{C}-\mathrm{O} \mathrm{WBI}$, increasing charge depletion on the transition metal, and increasing charge accumulation on the oxygen atoms of the $\{\mathrm{M}-\mathrm{CHO}\}^{-}$moiety (Table S5-6).

ETS-NOCV calculations were performed on complexes 3a-h to obtain quantitative data on the nature and strength of the metal-ligand interaction (Table S7-8). Before embarking on this analysis, it is useful to consider the frontier molecular orbitals of a bent $\{\mathrm{CHO}\}^{-}$triatomic; the HOMO shows significant carbon based lone-pair character, while the LUMO is a $\pi^{*}$ orbital with the largest coefficient on the carbon atom (Figure S31). In all cases for 3a-h the principal contribution $\left(\Delta \rho_{1}\right)$ to the bonding interaction is the $\sigma$ donation of the HOMO of the $\{\mathrm{CHO}\}^{-}$ligand to a transition-metal d-orbital. The secondary $\left(\Delta \rho_{2}\right)$ and tertiary $\left(\Delta \rho_{3}\right)$ interactions involve $\pi$ back-donation from a metal-based orbital to the orthogonal $\pi^{*}$ - 
orbitals of the $\left\{\mathrm{CHO}^{-}\right.$ligand. ${ }^{45}$ These donor-acceptor interaction can be visualised in the deformation density plots (Figure 2b, Table S11-13). The total orbital interaction between the formyl ligand and transition metal fragment, $\Delta \mathrm{E}_{\text {orb }}$, broadly increases across the first-row transition metals (3a vs $\mathbf{3 e}$; $\mathbf{3 d}$ vs 3f) and down the triad ( $\mathbf{3 f}$ vs $\mathbf{3 g}$ vs $\mathbf{3 h}$ ). These findings are in line with those from NBO calculations and solid-state data, and in combination suggest increased oxycarbene character increases the strength of the bonding interaction. ${ }^{46}$

(a)

NPA Charges and WBI

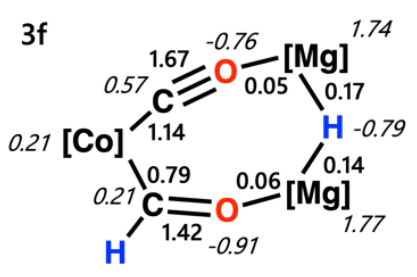

$3 g$

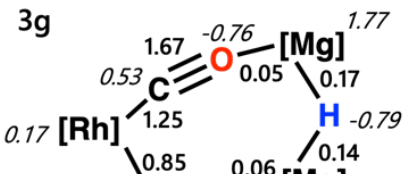
$0.23 \mathrm{C}=0.00[\mathrm{Mg}]$ $\mathrm{H}^{\prime}{ }^{1.44}-0.89$

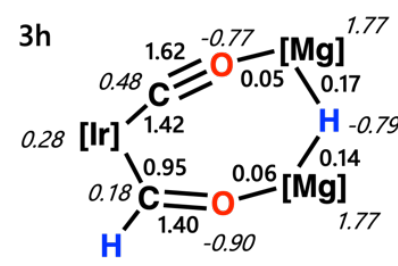

(b)

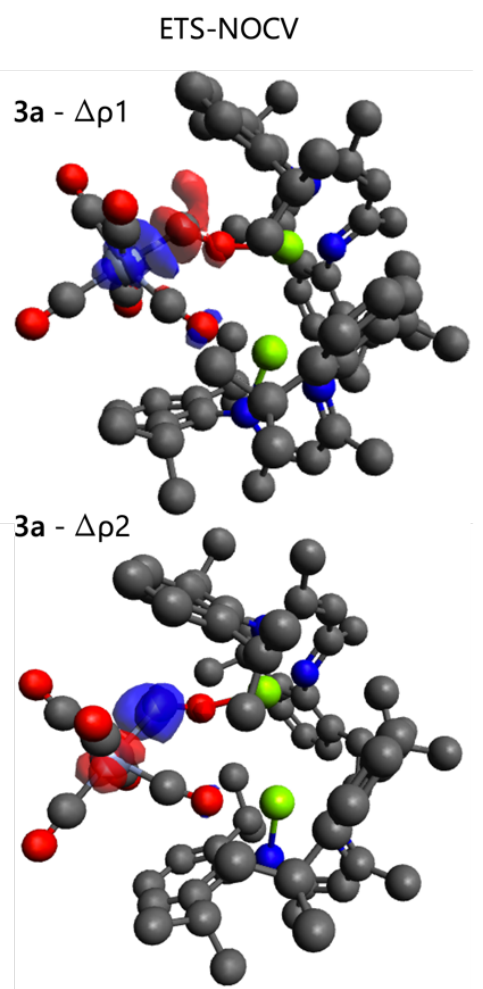

Figure 2. a) Select NPA charges and Wiberg Bond Indices for complexes 3f-h; b) Select ETS-NOCV deformation density data for complex 3a. Charge flow is from red to blue. Complete NBO, ETS-NOCV, and QTAIM data can be found in the supporting information.

To further assess their stability in solution, half-lives for complexes of $3 a-h$ in $\mathrm{C}_{6} \mathrm{D}_{6}$ at $22{ }^{\circ} \mathrm{C}$ have been measured (Table S4, Figure S22-30). In all cases decomposition kinetics followed a first-order decay, consistent with an intramolecular decomposition pathway: $3 a\left(t_{1 / 2}=2 \mathrm{~h}\right), \mathbf{3 b}\left(\mathrm{t}_{1 / 2}=2 \mathrm{~h}\right), \mathbf{3 c}\left(\mathrm{t}_{1 / 2}=57 \mathrm{~h}\right), \mathbf{3 d}$ $\left(t_{1 / 2}=136 \mathrm{~h}\right), \mathbf{3 e}\left(t_{1 / 2}=224 \mathrm{~h}\right), 3 \mathrm{f}\left(\mathrm{t}_{1 / 2}=330 \mathrm{~h}\right), \mathbf{3 g}\left(\mathrm{t}_{1 / 2}=217 \mathrm{~h}\right), 3 \mathrm{~h}\left(\mathrm{t}_{1 / 2}=533 \mathrm{~h}\right)$. The most stable complexes in this series $\mathbf{3 d} \mathbf{d} \mathbf{h}$ are those which contain electron-rich and sterically demanding ligands on the transition metal fragment. It has been previously suggest that transition metal formyl complexes can be stabilised by inclusion of a sterically demanding ligand, commonly a bulky phosphine. . $^{3,4,33,47,48}$ The half-life for 
complex $3 a\left(t_{1 / 2}=2 \mathrm{~h}\right)$, was identical in $\mathrm{C}_{6} \mathrm{D}_{6}$ and THF solvent and did not change when running the reaction under $1 \mathrm{~atm}$. of $\mathrm{CO}$. These results suggest that neither the solvent nor the concentration of $\mathrm{CO}$ in solution has an effect on the formyl ligand stability.
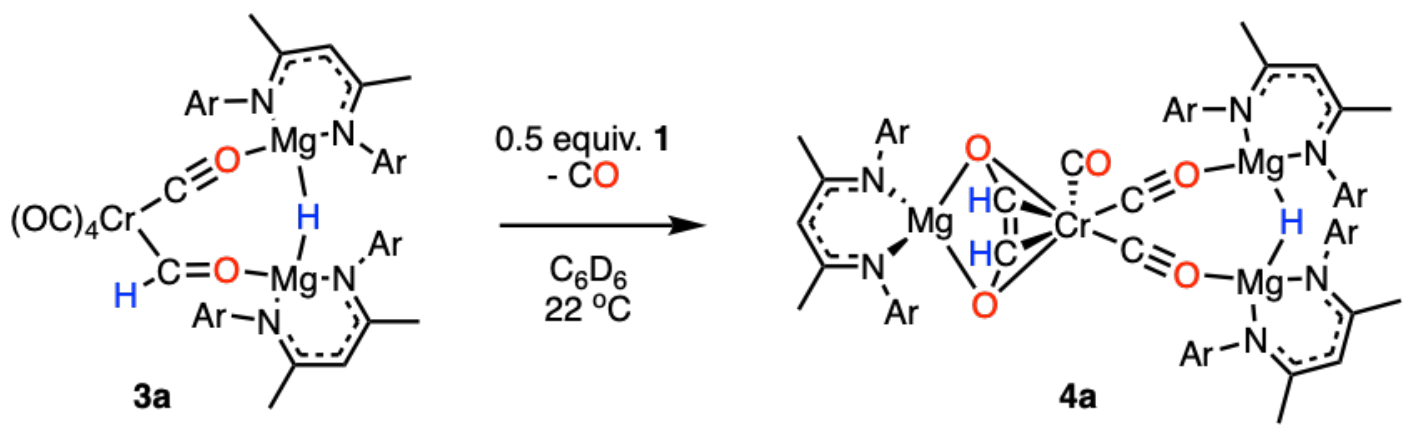

Scheme 3. Transformation of $3 a$ to $4 a$, a C-C coupled product.

Remarkably, onward reaction of $\mathbf{3 a}$ in solution reproducibly yielded a single well-defined product $4 \mathbf{a}$ (Scheme 3). 4a can be synthesised via three routes: thermal decomposition of 3a, reaction of $3 a$ with 0.5 equiv. of 1, and direct 1:1 reaction of 1 with 2a overnight; yields ranged 62-70\% (NMR), 31-51 \% (isolated crystals). 4a has been characterised by multinuclear NMR spectroscopy and single crystal x-ray diffraction (Figure 3). This complex comprises an ethenediolate $\left\{\mathrm{C}_{2} \mathrm{O}_{2}\right\}^{2-}$ unit bridging chromium and magnesium centres. From the perspective of chromium, the new ligand is reminiscent of a 6-electron $(2 \pi+2$ Oxygen LP) analogue of a butadiene type motif. Two chromium isocarbonyl ligands are bridged by a $\mathrm{Mg}-\mathrm{H}-\mathrm{Mg}$ unit, reminiscent of complexes 3a-h.

In solution, HSQC experiments on 4a led to the assignment of the ethenediolate protons as two singlet resonances at $\delta_{\mathrm{H}}=4.33(1 \mathrm{H})$ and $5.45 \mathrm{ppm}(1 \mathrm{H})$, associated carbon resonances occur at $\delta_{\mathrm{C}}=110.2$ and $110.5 \mathrm{ppm}$. The spectroscopic data are consistent with that reported for related magnesium ethenediolate complexes by Hill and Jones. ${ }^{49,50}$ The hydride bridging the two magnesium centres appears as a singlet resonance at $\delta_{H}=2.72 \mathrm{ppm}$. In the solid state, the key ethenediolate ligand chelates between a chromium and magnesium centre. Respective C-C and C-Cr bond lengths of 1.369(5) and 2.104(3) 2.109(3) $\AA$ indicate an alkene like ligand binding in a $\eta^{2}$-fashion to the central chromium atom. The $\left\{\mathrm{C}_{2} \mathrm{H}_{2} \mathrm{O}_{2}\right\}^{2-}$ unit coordinates through oxygen to a magnesium centre with O-Mg bond lengths of 1.986(2) and 1.992(2) A. The observed decomposition pathway stands in stark contrast to the expected $\alpha$ elimination reaction. It remains possible that the magnesium sites of 3a play a key role in the $\mathrm{C}-\mathrm{C}$ bond forming process and the mechanism of this reaction is currently under investigation in our labs. ${ }^{21}$ 


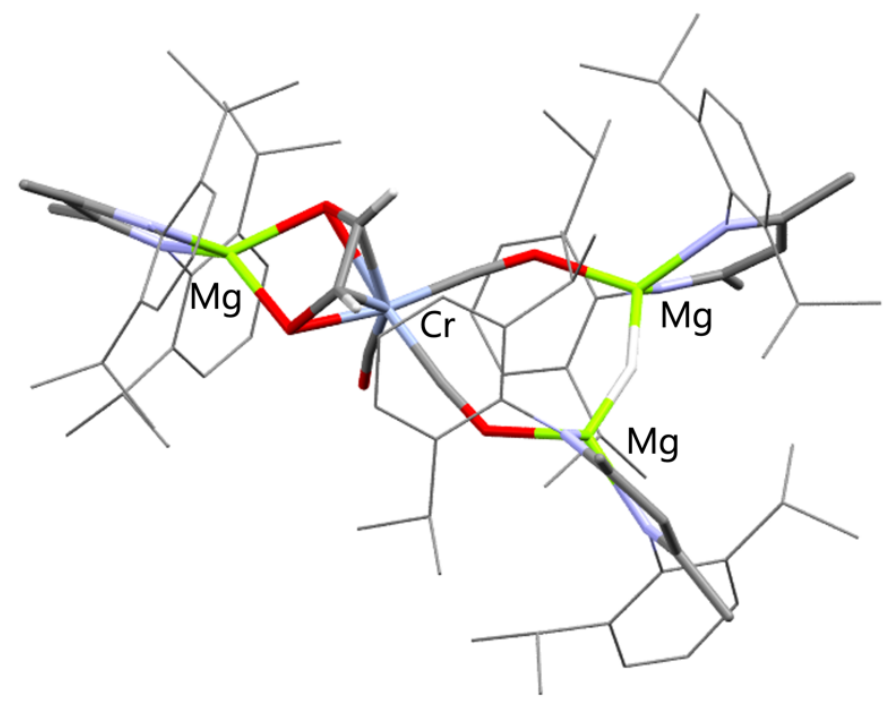

Figure 3. X-ray crystal structures of $\mathbf{4 a}$. Solvent molecules and most hydrogen atoms removed for clarity.

\section{Conclusions}

In summary, we report the first comprehensive series of transition-metal formyl complexes $(\mathrm{M}=\mathrm{Cr}, \mathrm{Mn}$, $\mathrm{Fe}, \mathrm{Co}, \mathrm{Rh}, \mathrm{W}, \mathrm{Ir}$ ). These include unprecedented examples of crystallographically characterised $\mathrm{Cr}$, $\mathrm{Co}$ and Ir formyl complexes. In all cases, the metal bound formyl ligand is stabilised by a heterometallic effect. Through use of a molecular magnesium hydride, the formyl oxygen is coordinated to a magnesium cation, resulting in oxycarbene character and significant stabilisation. We investigate this oxycarbene electronic structure through a series of density functional theory calculations (NBO, ETS-NOCV, QTAIM), concluding that more electron rich metal centres result in more oxycarbene character, and thus stabilisation of the metal-formyl ligand. Remarkably, decomposition of a chromium formyl complex yields C-C coupling and an isolable chromium ethenediolate complex. This serves as the first direct example of carbon-carbon bond formation at a molecular metal-formyl complex and is of direct relevance to CO homologation and Fischer-Tropsch chemistry.

\section{Associated Content}

Supporting Information. X-ray crystallographic data for $\mathbf{3 a - h}$ and $\mathbf{4 a}$ are available from the Cambridge Crystallographic Data Centre (CCDC 2116002 - 2116010) as a .cif file, full details of the experiments and calculations are available as a .pdf. 


\section{Author Information}

The authors declare no financial conflicts. Correspondence should be addressed to m.crimmin@imperial.ac.uk.

\section{Acknowledgements}

We thank Imperial College London for the award of a Schrödinger's Scholarship (JP). Dr. Andreas

Phanopoulos is thanked for insightful discussions. We also thank the EPSRC for project funding (EP/S036628/1).

\section{References}

1 N. M. West, A. J. M. Miller, J. A. Labinger and J. E. Bercaw, Coord. Chem. Rev., 2011, 255, 881898.

2 C. P. Casey and S. M. Neumann, J. Am. Chem. Soc, 1976, 5395-5396.

3 W. Tam, W.-K. Wong and J. A. Gladysz, J. Am. Chem. Soc, 1979, 101, 1589-1591.

$4 \quad$ H. Berke and G. Weiler, Angew. Chem. Int. Ed., 1982, 21, 150-151.

5 M. D. Farnos, B. A. Woods and B. B. Wayland, J. Am. Chem. Soc., 1986, 108, 3659-3663.

6 A. R. Cutler, P. K. Hanna and J. C. Vites, Chem. Rev., 1988, 88, 1363-1403.

7 B. H. Davis and M. L. Occelli, Advances in Fischer-Tropsch Synthesis, Catalysts, and Catalysis, 2020.

8 J. A. Labinger, J. Organomet. Chem., 2017, 847, 4-12.

9 D. Unruh, K. Pabst and G. Schaub, Energy and Fuels, 2010, 24, 2634-2641.

10 O. R. Inderwildi, S. J. Jenkins and D. A. King, Angew. Chem. Int. Ed., 2008, 47, 5253-5255.

11 S. Srinivas, R. K. Malik and S. M. Mahajani, Energy Sustain. Dev, 2007, 66-71.

12 A. J. Ragauskas, C. K. Williams, B. H. Davison, G. Britovsek, J. Cairney, C. A. Eckert, W. J. Frederick, J. P. Hallett, D. J. Leak, C. L. Liotta, J. R. Mielenz, R. Murphy, R. Templer and T. Tschaplinski, Science, 2006, 311, 484-489.

13 J. P. Collman and S. R. Winter, J. Am. Chem. Soc, 1973, 4089-4090.

14 T. J. Collins and W. R. Roper, J. Chem. Soc. Chem. Commun., 1976, 1044-1045.

15 P. Leoni, A. Landi and M. Pasquali, J. Organomet. Chem., 1987, 321, 365-369.

16 J. A. Partin and M. G. Richmond, J. Organomet. Chem., 1988, 353, 13-16. 
A. Asdar, C. Lapinte and L. Toupet, Organometallics, 1989, 8, 2708-2717.

J. A. Gladysz, G. M. Williams, W. Tam and D. L. Johnson, J. Organomet. Chem., 1977, 140, C1-C6.

R. L. Pruett, R. C. Schoening, J. L. Vidal and R. A. Fiato, J. Organomet. Chem., 1979, 182, 57-60.

C. P. Casey, S. M. Neumann, M. A. Andrews and R. McAlister, Donald, Pure Appl. Chem., 1980, 52, 625-633.

B. A. Narayanan, C. A. Amatore and J. K. Kochi, Organometallics, 1984, 802-804.

G. Nelson and C. E. Sumner, Organometallics, 1986, 5, 1983-1990.

P. A. Kongshaug and R. G. Miller, Organometallics, 1987, 6, 372-378.

M. G. Richmond and J. K. Kochi, Organometallics, 1987, 6, 777-788.

M. G. Richmond and J. K. Kochi, J. Organomet. Chem., 1987, 323, 219-232.

H. Berke and R. Hoffmann, J. Am. Chem. Soc., 1978, 100, 7224-7236.

S. L. Van Voorhees and B. B. Wayland, Organometallics, 1987, 204-206.

K. R. Lane and R. R. Squires, Polyhedron, 1988, 7, 1609-1618.

G. Pacchioni, P. Fantucci, J. Koutecký and V. Ponec, J. Catal., 1988, 112, 34-43.

P. T. Barger, B. D. Santarsiero, J. Armantrout and J. E. Bercaw, J. Am. Chem. Soc, 1984, 106, 51785186.

D. A. Katahlra, K. G. Moloy and T. J. Marks, Organometallics, 1982, 1, 1723-1726.

E. L. Werkema, L. Maron, O. Eisenstein and R. A. Andersen, J. Am. Chem. Soc., 2007, 129, 25292541.

J. S. Sapsford, S. J. Gates, L. R. Doyle, R. A. Taylor, S. Díez-González and A. E. Ashley, Inorganica Chim. Acta, 2019, 488, 201-207.

P. J. Fagan, K. G. Moloy and T. J. Marks, J. Am. Chem. Soc, 1981, 103, 6959-6962.

P. T. Wolczanski, R. S. Threlkel and J. E. Bercaw, J. Am. Chem. Soc, 1979, 101, 218-220.

P. R. Elowe, N. M. West, J. A. Labinger and J. E. Bercaw, Organometallics, 2009, 28, 6218-6227.

F. G. A. Stone, R. West and J. A. Gladysz, Advances in Organometallic Chemistry Volume 20, 1982.

R. M. Silverstein, G. C. Bassler and T. C. Morrill, Spectrometric Identification of Organic Compounds, 3rd Edition, 1974.

M. Garçon, N. W. Mun, A. J. P. White and M. R. Crimmin, Angew. Chem. Int. Ed., 2021, 60, 6145-6153.

M. Garçon, C. Bakewell, G. A. Sackman, A. J. P. White, R. I. Cooper, A. J. Edwards and M. R. Crimmin, Nature, 2019, 574, 390-393. 
42 A. Hicken, A. J. P. White and M. R. Crimmin, Angew. Chem. Int. Ed., 2017, 56, 15127-15130.

43 J. Da Chai and M. Head-Gordon, Phys. Chem. Chem. Phys., 2008, 10, 6615-6620.

44 J. Da Chai and M. Head-Gordon, J. Chem. Phys., 2008, 128, 084106.

45 For Ir, further splitting of the metal-based d-orbitals (due to overlap with ligand SALCS of CO) results in both $\mathrm{p} 1$ and $\mathrm{p} 2$ interactions being s-donation from the $\mathrm{HOMO}$ of $\{\mathrm{CHO}\}$ to empty orbitals of the Ir fragment. p3 is p-backdonation.

46 While this treatment allows analysis of the key bonding interaction between the formyl ligand and the transition metal, it does not lead to the lowest to the lowest total orbital interaction energies, $\Delta \mathrm{E}_{\text {orb }}$. A second set of ETS-NOCV calculations split complexes 3 into anionic and cationic fragments by dividing at the $\mathrm{Mg}-\mathrm{O}$ bond, giving consistently lower $\Delta \mathrm{E}_{\text {orb }}$ values (S8, Figure S34).

47 S. G. Davies and A. J. Smallridge, J. Organomet. Chem., 1990, 397, 13-19.

48 B. H. Berke, G. Huttner, O. Scheidsteger and G. Weiler, Angew. Chem. Int. Ed., 1984, 735-736.

49 M. D. Anker, M. S. Hill, J. P. Lowe and M. F. Mahon, Angew. Chemie, 2015, 127, 10147-10149.

50 R. Lalrempuia, C. E. Kefalidis, S. J. Bonyhady, B. Schwarze, L. Maron, A. Stasch and C. Jones, J. Am. Chem. Soc., 2015, 137, 8944-8947. 